\title{
Factors Associated with Quality of Life in Patients with Systemic Arterial Hypertension
}

Gustavo O. Silva, ${ }^{\circledR}$ Aluísio Andrade-Lima, ${ }^{2 \oplus}$ Antônio Henrique Germano-Soares, ${ }^{3 \oplus}$ Dalton de Lima-Junior, ${ }^{4}$ Sergio L. C. Rodrigues, ${ }^{5}$ Raphael M. Ritti-Dias, ${ }^{1 \oplus}$ Breno Q. Farah ${ }^{5 \odot}$

Universidade Nove de Julho, 'São Paulo, SP-Brazil

Universidade Federal de Sergipe, ${ }^{2}$ Aracaju, SE - Brazil

Universidade de Pernambuco, ${ }^{3}$ Recife, $P$ E - Brazil

Universidade Federal da Paraíba, ${ }^{4}$ João Pessoa, PB - Brazil

Universidade Federal Rural de Pernambuco, ${ }^{5}$ Recife, PE - Brazil

\section{Abstract}

Background: Hypertensive patients present, in addition to worse cardiovascular health, lower health-related quality of life compared to normotensive subjects. Factors such as functional capacity, functional status, pain, participation in social activities, mental and emotional health, fatigue and energy level, along with perception of general health, seem to be relevant for evaluation in this population. However, evidence is unclear in hypertensive patients.

Objective: To analyze the factors associated with quality of life in hypertensive patients.

Methods: Forty-five patients were recruited. The dependent variables of the present study are the quality of life domains. Demographic data and clinical conditions were considered independent variables. The Medical Outcomes Short-Form Health Survey (SF-36) questionnaire was used to measure quality of life. Handgrip strength, blood pressure and anthropometric indicators were evaluated. Crude and adjusted linear regression analysis was used.

Results: It was verified that education level, body mass index and muscle strength were associated with the functional capacity domain $(\mathrm{p}<0,05)$, whereas systolic blood pressure was associated with the physical domain $(\mathrm{p}<0,05)$. Women presented lower quality of life on the pain domain compared to men and educational level was associated with the social domain $(\mathrm{p}<0,05)$.

Conclusion: Hypertensive patients with lower levels of body mass index, higher levels of education and muscle strength presented a better quality of life on the physical domain, while the social aspects presented a positive relationship with education level. Women presented a worse quality of life on the pain domain compared to men. (Int J Cardiovasc Sci. 2020; 33(2):133-142)

Keywords: Cardiovascular Diseases/physiopathology; Hypertension; Vital capacity; Exercise; Quality of Life; Risk Factors.

\section{Introduction}

It is estimated that cardiovascular diseases are responsible for approximately $30 \%$ of worldwide deaths. ${ }^{1}$ In Brazil, the mortality rate reached at least $20 \%$ of individuals older than 30, which corresponded to 962,931 deaths, in 2009 alone, according to the Ministry of Health. ${ }^{2}$ Thereby, the costs associated with cardiovascular diseases were around 30.8 billion, burdening the Health System. One of the main risk factors for cardiovascular and cerebrovascular diseases is systemic arterial hypertension, ${ }^{3}$ which affects around $25 \%$ of the general population and $65 \%$ of the elderly population. ${ }^{4}$

Besides the cardiovascular problems, a recent metaanalysis ${ }^{5}$ demonstrated that hypertensive patients present worse quality-of-life indicators compared to 
normotensives, mainly in the parameters related to the physical domain. However, the quality-of-life concept is extended, once it refers to personal satisfaction, defined in relation to the daily life, which is influenced by individual evaluation of physical, psychological, social and spiritual

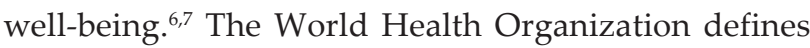
quality of life as "an individual's perception of their position in life in the context of the culture and value systems in which they live and in relation to their goals, expectations, standards and concerns."

In this context, different parameters can directly affect the quality of life of these patients. Among these parameters, the physical aspect, for example, evaluated through the physical limitations in daily activities, dissatisfaction with functional capacity and mobility, can negatively reflect the quality of life. ${ }^{8}$ Additionally, the frequency with which an hypertensive patient feels body pain or discomforts can interfere with the execution of daily living activities. ${ }^{9}$ Thus, these limitations, caused by health, physical or emotional problems related to hypertension, must be better understood for a greater understanding of the quality of life of these individuals. ${ }^{10}$

Beyond the physical aspects, deterioration of an individual's mental health, as a reflection of hypertension, can lead to reduced frequency of participation in relevant social activities for the individual's personal life, for example. ${ }^{11}$ In fact, the emotional aspects can be related to damages to one of the four main dimensions of mental health (anxiety, depression, loss of behavioral or emotional control and physiological well-being). ${ }^{12}$ Another aspect that deserves attention is related to vitality as energy level and fatigue, which can support the evaluation of the subjective well-being of hypertensive individuals. ${ }^{13}$ Lastly, evaluating the individual's general health perception can be interesting, considering the impact of the presence of diseases and its complications in the individual's health. ${ }^{10}$

Therefore, questionnaires that aim to analyze quality of life are necessary, such as the 36-item Short Form Health Survey (SF-36), ${ }^{14}$ which consists of 36 items, one of which measures the health transition, and the other 35 are grouped into scales and divided into eight domains: functional capacity, physical aspects, pain, general health, vitality, social aspects, emotional aspects and mental health. These eight domains can also be aggregated in summary: measurements of physical and emotional factors. ${ }^{15}$

In this context, some studies have investigated the factors associated with quality of life in hypertensive individuals, given its relevance to the health of those patients. Indeed, the influence of the factors associated with quality of life can predict long-term functional independence, adherence to anti-hypertensive therapy and incidence of survival in hypertensives. ${ }^{16-18}$ Previous studies have suggested that clinical aspects directly affect the quality of life in hypertensive individuals, ${ }^{19}$ such as comorbidities (heart failure, acute myocardial infarction and angina pectoris), ${ }^{20}$ medication, ${ }^{21,22}$ disease knowledge level and blood pressure values. ${ }^{22}$

On the other hand, it is unknown whether physical fitness and demographic characteristics are related to quality of life in hypertensive individuals. Studies with other population subgroups have demonstrated that increases in muscle strength and body weight reduction, for example, have been constantly related to an improvement in daily activities in healthy elderly individuals, ${ }^{23,24}$ leading to greater functional independence and physical fitness, which lead to better quality of life. Indeed, it is known that older individuals, consequently with worse physical fitness, present reduced quality-oflife indicators - due to decreased mass - of strength and muscle resistance, leading to increased fatigue during the performance of daily activities. ${ }^{25}$

Therefore, identifying factors related to quality of life, such as physical fitness, may help health professionals to propose interventions. Thus, the aim of the present study was to analyze the factors associated with quality of life in hypertensive individuals. Our hypothesis is that physical fitness is the main component associated with quality of life in hypertensive individuals.

\section{Methods}

This is a correlational cross-sectional study that analyzed the initial data of an interventional study that analyzed the effects of isometric handgrip training in the blood pressure of hypertensive individuals. ${ }^{26}$

All individuals were recruited by flyers in Universidade de Pernambuco in the Santo Amaro Campus, public hospitals, or through media advertisements (online journals and social media) in the city of Recife and metropolitan region. The project was approved by the Research Ethics committee of Universidade de Pernambuco and all patients signed an informed consent form.

\section{Subjects}

The inclusion criteria of the study were: a) use of anti-hypertensive medication; b) age above 18 years; 
c) absence of any other chronic disease; d) not having performed physical exercise in the last six months. Subjects that did not adequately answer the quality-of-life questionnaire were excluded from the study.

\section{Data collection}

The data collection occurred between August 2015 and August 2016. The dependent variables of the study are the quality-of-life domains. Demographic data and clinical conditions were considered as independent variables.

We evaluated the patients' sex, age and educational level, as well as health history (time of hypertension and medications). Before all cardiovascular evaluations, the patients were instructed to a) have a light meal before arriving at the laboratory; b) avoid physical activities of moderate to vigorous intensity for at least $24 \mathrm{~h}$ before the laboratory visit; and c) avoid smoking, caffeine and alcohol consumption for at least $12 \mathrm{~h}$. In the laboratory, the subjects initially remained in the supine position for a period of rest of $10 \mathrm{~min}$ to perform the measurements with a controlled temperature between 22 and $24^{\circ} \mathrm{C}$.

\section{Quality of life}

Quality of life was measured through the SF-36 questionnaire $^{27}$ after an individual interview with the hypertensive subjects by a trained researcher. For each of the SF-36 domains (functional capacity, physical aspects, pain, general health, vitality, social aspects, emotional aspects and mental health), the respective scores were calculated, which varied from 0 to 100 , where 0 corresponds to the worst health status and 100 to the best health status.

\section{Anthropometric measurements}

Body mass, height and waist circumference were obtained. Body mass was measured in a digital scale, Filizola brand, with $0,1 \mathrm{~kg}$ precision and height was determined in a stadiometer coupled to the scale with $0,1 \mathrm{~cm}$ precision. Waist circumference was obtained using the umbilical scar as reference. ${ }^{28}$ The body mass index was calculated by dividing body mass by square height in meters.

\section{Muscle strength}

Muscle strength was measured through a digital hand dynamometer (CAMRY, United States) adjustable and calibrated with a 0 to $100 \mathrm{~kg} / \mathrm{f}$ scale. The test was performed three times, for each arm, with a 1-minute interval between each try and the highest value found was considered the result. This procedure showed an intraclass correlation coefficient (test and retest with a 1-week interval) from 0,986 to $0,989 .{ }^{29}$

\section{Clinical blood pressure}

Clinical blood pressure was obtained in an Omron HEM 742 device. All the procedures followed the recommendations of the $7^{\text {th }}$ Brazilian Guidelines of Hypertension $^{30}$ and showed good reproducibility indicators. ${ }^{31}$ The intraclass correlation coefficient for systolic blood pressure was 0,85 and, for diastolic blood pressure, $0,92 .^{31}$

\section{Statistical analysis}

To analyze the factors associated with quality of life, we performed the crude and adjusted linear regression analysis. Initially, the crude analysis was performed to establish the variables included in the multiple models. Therefore, only the variables that showed $\mathrm{p} \leq 0.30$ were included. The significance level adopted and the criteria for the variable to remain in the model was $p<0.05$. Multicollinearity analysis was performed to identify the existence of a strong correlation between two (or more) independent variables, which could affect the relationship with the dependent variable. Thus, Variance Inflation Factors (VIF) lower than five were assumed with tolerance lower than 0.20. All analyses were performed in the Statistical Package for the Social Sciences (SPSS), version 20 , and the data are presented as mean \pm standard deviation and relative frequency.

\section{Results}

Table 1 shows the general characteristics of the hypertensive patients included in the study.

Tables 2 and 3 show the relationship between the demographic, clinical and physical fitness variables with the quality of life of hypertensives in the physical and emotional domains.

Figure 1 shows the variables that presented a statistically significant relationship. It was found that individuals with lower educational level, higher body mass index and lower muscle strength showed the worse quality of life in the functional capacity domain ( $p<0.05$ for all). Higher systolic blood pressure was related to higher values in the physical aspects domain $(p<0.05)$. Women presented 


\begin{tabular}{|c|c|}
\hline Variables & Values \\
\hline \multicolumn{2}{|l|}{ Demographic } \\
\hline Sex (\% women) & 70,5 \\
\hline Age (years) & $57,7 \pm 9,7$ \\
\hline Educational level (years of study) & $9,5 \pm 3,1$ \\
\hline \multicolumn{2}{|l|}{ Clinical parameters } \\
\hline Hypertension time (months) & $12,4 \pm 9,3$ \\
\hline Medications (units) & $1,8 \pm 0,7$ \\
\hline SBP (mmHg) & $132,0 \pm 16,3$ \\
\hline $\mathrm{DBP}(\mathrm{mmHg})$ & $74,4 \pm 9,6$ \\
\hline \multicolumn{2}{|l|}{ Health-related physical fitness } \\
\hline Muscle strength (kgf) & $31,7 \pm 10,5$ \\
\hline Body mass index $\left(\mathrm{kg} / \mathrm{m}^{2}\right)$ & $30,7 \pm 5,3$ \\
\hline \multicolumn{2}{|l|}{ Quality of life } \\
\hline Functional capacity (score) & $75,9 \pm 21,6$ \\
\hline Physical aspects (score) & $70,1 \pm 38,2$ \\
\hline Pain (score) & $29,4 \pm 21,3$ \\
\hline General health (score) & $56,3 \pm 10,6$ \\
\hline Vitality (score) & $54,4 \pm 12,3$ \\
\hline Social aspects (score) & $48,2 \pm 11,2$ \\
\hline Emotional aspects (score) & $77,3 \pm 38,5$ \\
\hline Mental health (score) & $57,1 \pm 10,3$ \\
\hline
\end{tabular}

SBP: systolic blood pressure; DBP: diastolic blood pressure. Values presented in frequency or mean and standard deviation.

worse quality of life in the pain domain compared to men and educational level was directly related to social aspects $(p<0.05)$. The other factors did not present statistically significant relationships with the quality-of-life domains ( $p>0.05$ for all).

\section{Discussion}

The main findings of the present study were a) educational level and muscle strength were positively related to functional capacity, while body mass index showed a negative correlation; b) patients with higher educational level presented higher scores in the social aspects domain; c) systolic blood pressure levels showed a positive relationship with the physical aspects domain; and, d) female patients presented worse scores in the pain domain.

The quality of life evaluation is an important outcome in different populations, mainly because of its prognostic value. For example, an improvement in this indicator is associated with greater survival rate in hypertensive patients, while a worse quality of life predicts lower survival rates. ${ }^{16}$ In the conceptual model proposed by Wilson and Cleary, ${ }^{32}$ several factors influence an individual's quality of life, including physical and social functioning, mental health and general health perception. In this context, the SF-36, which is an instrument that evaluates quality of life, includes eight domains (functional capacity, physical aspects, pain, general health, vitality, social aspects, emotional aspects and mental health) that detail these factors. ${ }^{14}$ These domains measure the capacity of performing tasks and daily activities in addition to subjective measures of wellbeing, including how the individuals feel physically and emotionally regarding their health. ${ }^{33}$

Considering functional capacity and social aspects, the present study observed that educational level is associated with these indicators in hypertensive individuals. This data is in accordance with a previous study $^{34}$ that evaluated 1,124 hypertensive individuals and identified that patients with lower educational level reported worse scores in the functional capacity domain. A possible explanation for those results is that individuals with higher educational levels have a better perception about healthy habits such as exercising and weight reduction along with the importance of social interaction, ${ }^{35-37}$ which are directly related to physical function and social aspects of the quality of life of hypertensive individuals. Additionally, patients with higher educational levels may have better access to good quality medical care, along with better knowledge of health and habits that can influence longevity, increasing life expectancy, ${ }^{38,39}$ and positively changing the quality of life of these patients.

Muscle strength levels were also associated with higher scores in the functional capacity domain in hypertensive individuals, corroborating with other studies. ${ }^{40,41}$ Indeed, a previous study ${ }^{40}$ with healthy elderly individuals observed that men and women with lower grip strength were more likely to report deteriorations in general health. Both findings are relevant since they suggest that healthy or hypertensive individuals with lower grip strength have a lower quality of life. In this context, these 
Table 2 - Factors associated with quality of life in the physical domain in hypertensive individuals

\begin{tabular}{|c|c|c|c|c|c|c|c|c|c|c|c|c|c|c|c|c|}
\hline \multirow{3}{*}{ Variables } & \multicolumn{4}{|c|}{ Functional Capacity } & \multicolumn{4}{|c|}{ Physical Aspects } & \multicolumn{4}{|c|}{ Pain } & \multicolumn{4}{|c|}{ General Health } \\
\hline & \multicolumn{2}{|c|}{ Crude } & \multicolumn{2}{|c|}{ Adjusted $^{1}$} & \multicolumn{2}{|c|}{ Crude } & \multicolumn{2}{|c|}{ Adjusted $^{2}$} & \multicolumn{2}{|c|}{ Crude } & \multicolumn{2}{|c|}{ Adjusted $^{3}$} & \multicolumn{2}{|c|}{ Crude } & \multicolumn{2}{|c|}{ Adjusted } \\
\hline & b & p & b & $\mathrm{p}$ & $\mathbf{b}$ & $\mathrm{p}$ & b & $\mathrm{p}$ & b & p & b & $\mathrm{p}$ & $\mathbf{b}$ & p & b & p \\
\hline \multicolumn{17}{|l|}{ Demographic } \\
\hline $\begin{array}{l}\text { Sex }(\% \\
\text { women) }\end{array}$ & 0.229 & 0.047 & ns & ns & 0.208 & 0.072 & ns & ns & -0.233 & 0.043 & -0.243 & 0.043 & -0.169 & 0.149 & ns & ns \\
\hline Age (years) & -0.040 & 0.732 & - & - & 0.008 & 0.944 & & & 0.043 & 0.717 & & & -0.126 & 0.291 & ns & ns \\
\hline $\begin{array}{l}\text { Educational } \\
\text { level (years) }\end{array}$ & 0.183 & 0.135 & 0.231 & 0.044 & 0.011 & 0.932 & & & -0.107 & 0.387 & & & 0.101 & 0.417 & & \\
\hline \multicolumn{17}{|c|}{ Clinical parameters and physical fitness } \\
\hline $\begin{array}{l}\text { Hypertension } \\
\text { time (years) }\end{array}$ & -0.071 & 0.549 & - & - & 0.056 & 0.638 & & & -0.164 & 0.165 & ns & ns & 0.003 & 0.980 & & \\
\hline $\begin{array}{l}\text { Medications } \\
\text { (units) }\end{array}$ & -0.016 & 0.890 & - & - & -0.191 & 0.105 & ns & ns & -0.019 & 0.875 & & & -0.080 & 0.509 & & \\
\hline SBP (mmHg) & -0.074 & 0.539 & - & - & 0.282 & 0.017 & 0.282 & 0.017 & -0.146 & 0.226 & ns & ns & 0.025 & 0.838 & & \\
\hline $\mathrm{DBP}(\mathrm{mmHg})$ & 0.093 & 0.440 & - & - & 0.137 & 0.254 & ns & ns & -0.157 & 0.191 & ns & ns & -0.003 & 0.981 & & \\
\hline $\begin{array}{l}\text { Muscle } \\
\text { strength } \\
\text { (kgf) }\end{array}$ & 0.236 & 0.042 & 0.290 & 0.011 & 0.184 & 0.114 & ns & ns & -0.189 & 0.104 & ns & ns & -0.202 & 0.085 & ns & ns \\
\hline $\begin{array}{l}\text { Body mass } \\
\text { index } \\
\left(\mathrm{kg} / \mathrm{m}^{2}\right)\end{array}$ & -0.302 & 0.007 & -0.390 & 0.001 & -0.134 & 0.243 & ns & ns & 0.175 & 0.126 & ns & ns & 0.193 & 0.095 & ns & ns \\
\hline
\end{tabular}

individuals may present benefits from interventions to increase muscle mass and strength, and consequently, quality of life. Additionally, it is noteworthy that Trosclair et al., ${ }^{42}$ demonstrated the relationship between grip strength and global strength, which reinforces the grip strength test measurement, mainly due to its ease of application and reproducibility. ${ }^{29}$ Also, the relationship between muscle strength and the functional capacity domain may be explained by greater efficiency in the performance of moderate and vigorous daily activities. Thereby, climbing stairs, carrying groceries, walking long distances and performing domestic activities more easily and vigorously can positively influence the quality of life of those patients. ${ }^{43}$

In the present study, hypertensive individuals with lower body mass index showed lower scores in the functional capacity domain; in other words, overweight and obesity impair daily activities, reducing the quality of life of hypertensive individuals. Similarly, Awotidebe et al., ${ }^{44}$ observed that all quality-of-life domains were worse in hypertensive individuals with higher body mass. Psychological and psychosocial problems related to higher body mass index are probably factors associated with a decrease in the quality of life of those individuals. ${ }^{45,46}$ Indeed, obesity has been widely related to anxiety and depression, which increases dissatisfaction levels, causes loss of interest and lack of enjoyment, negatively affecting quality of life. Besides, higher body mass can also lead to negative consequences related to general mobility, mortality and health costs, which can also directly affect the perception of quality of life. ${ }^{47}$

Contrary to expectations, systolic blood pressure showed a positive association with the physical aspects of quality of life, disagreeing with other results found in the literature..$^{22,48,49}$ Indeed, a previous study ${ }^{50}$ observed that patients with higher blood pressure have a lower 
Table 3 - Factors associated with quality of life in the emotional domain in hypertensive individuals

\begin{tabular}{|c|c|c|c|c|c|c|c|c|c|c|c|c|c|c|c|c|}
\hline \multirow{3}{*}{ Variables } & \multicolumn{4}{|c|}{ Vitality } & \multicolumn{4}{|c|}{ Social aspects } & \multicolumn{4}{|c|}{ Emotional aspects } & \multicolumn{4}{|c|}{ Mental Health } \\
\hline & \multicolumn{2}{|c|}{ Crude } & \multicolumn{2}{|c|}{ Adjusted } & \multicolumn{2}{|c|}{ Crude } & \multicolumn{2}{|c|}{ Adjusted $^{1}$} & \multicolumn{2}{|c|}{ Crude } & \multicolumn{2}{|c|}{ Adjusted } & \multicolumn{2}{|c|}{ Crude } & \multicolumn{2}{|c|}{ Adjusted } \\
\hline & b & $\mathrm{p}$ & b & p & b & $\mathrm{p}$ & b & $\mathbf{P}$ & b & $\mathrm{p}$ & b & p & b & p & b & $\mathbf{P}$ \\
\hline \multicolumn{17}{|l|}{ Demographic } \\
\hline $\begin{array}{l}\text { Sex }(\% \\
\text { women) }\end{array}$ & 0.121 & 0.300 & ns & ns & 0.093 & 0.426 & & & 0.034 & 0.773 & & & -0.073 & 0.535 & & \\
\hline Age (years) & 0.017 & 0.885 & & & -0.013 & 0.916 & & & 0.120 & 0.308 & & & 0.174 & 0.141 & ns & ns \\
\hline $\begin{array}{l}\text { Educational } \\
\text { level (years) }\end{array}$ & 0.150 & 0.227 & ns & ns & 0.344 & 0.004 & 0.332 & 0.006 & 0.036 & 0.770 & & & -0.027 & 0.829 & & \\
\hline \multicolumn{17}{|c|}{ Clinical parameter and physical fitness } \\
\hline $\begin{array}{l}\text { Hypertension } \\
\text { time (years) }\end{array}$ & -0.079 & 0.507 & & & 0.153 & 0.196 & ns & ns & -0.076 & 0.253 & ns & ns & 0.023 & 0.848 & & \\
\hline $\begin{array}{l}\text { Medications } \\
\text { (units) }\end{array}$ & -0.107 & 0.371 & & & -0.121 & 0.306 & & & -0.179 & 0.130 & ns & ns & -0.115 & 0.335 & & \\
\hline SBP (mmHg) & 0.030 & 0.807 & & & -0.030 & 0.805 & & & 0.136 & 0.259 & ns & ns & 0.061 & 0.617 & & \\
\hline $\mathrm{DBP}(\mathrm{mmHg})$ & -0.041 & 0.735 & & & -0.042 & 0.730 & & & -0.082 & 0.497 & & & -0.035 & 0.771 & & \\
\hline $\begin{array}{l}\text { Muscle } \\
\text { strength } \\
\text { (kgf) }\end{array}$ & 0.073 & 0.537 & & & 0.053 & 0.649 & ns & ns & 0.017 & 0.886 & & & -0.162 & 0.167 & ns & ns \\
\hline $\begin{array}{l}\text { Body mass } \\
\text { index } \\
\left(\mathrm{kg} / \mathrm{m}^{2}\right)\end{array}$ & 0.067 & 0.565 & & & 0.131 & 0.253 & & & -0.067 & 0.559 & & & -0.208 & 0.069 & ns & ns \\
\hline
\end{tabular}

quality of life, which is a reflection of greater impairments in the physical aspects of these individuals, due to the disease. ${ }^{51,52}$ A possible explanation for the association found in the present study is the fact that patients with higher blood pressure may be aware of their status and look for alternatives besides medication or exercise in order to improve their blood pressure levels, such as nutritional interventions, smoking cessation, improvements in sleep quality and stress control. This behavior could have affected the relationships due to the fact that they are strategies recommended in literature, ${ }^{53}$ which could improve their physical aspect without improving blood pressure levels initially. Interestingly, when hypertensive individuals were submitted to exercise training programs, aspects related to the quality of life improved in 6 to 10 weeks after the beginning of the program, ${ }^{54}$ while modifications in biological variables, such as blood pressure, occurred later (over 12 weeks from the intervention). ${ }^{55}$

Women showed worse quality of life in the pain domain compared to men. These results are similar to a previous epidemiological study with 4,506 adults that observed that muscle pain, headache and pain perception in the SF-36 were worse in women than in men. ${ }^{56}$ To explain this relationship, the literature indicates that the pain perception is influenced by complex interactions between biological variables (sexual hormones, genetics, pain pathways and variations in the central nervous system) and psychosocial variables (depression, anxiety, depreciation on the job market, gender role expectations, social learning factors and importance given to pain), where women are more susceptible to the symptoms, especially in advanced age due to menopause and hormonal dysfunctions. ${ }^{56,57}$ 

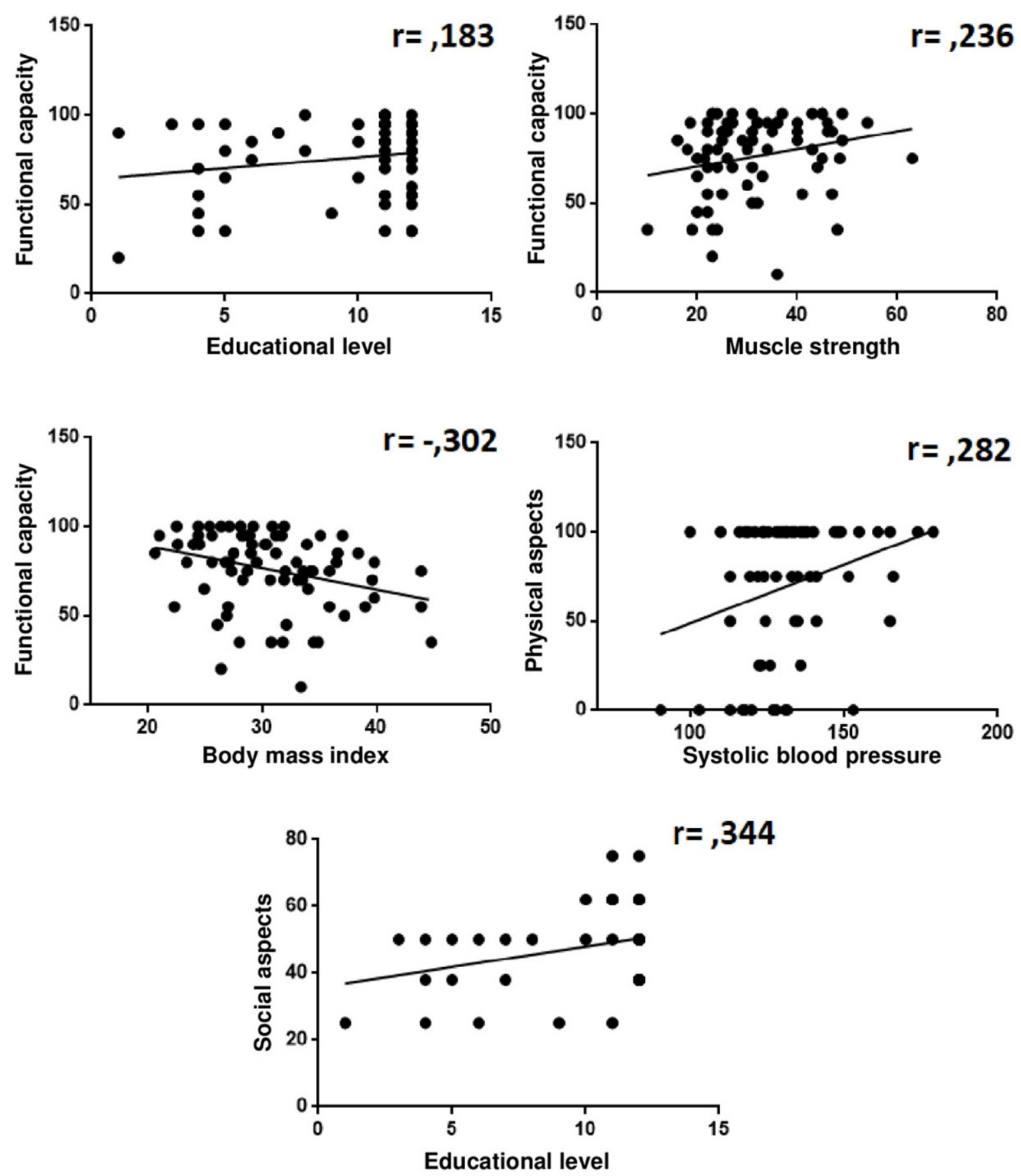

Figure 1 - Relationship between statistically significant variables.

This study presents some limitations that must be considered. The sample of the present study was composed of medicated hypertensive individuals that enrolled in an exercise intervention aiming to reduce their cardiovascular risk, then the specific sample characteristics limit the generalizability of the findings to other hypertensive individuals, especially those with other associated pathologies (cardiac or cerebrovascular diseases, diabetes) or even to resistant hypertensive individuals, since only one patient presented this characteristic. The sample 
size did not allow us to perform stratified analysis by medication class. Lastly, the fact that this study presents an associative nature makes it impossible to inflict causality to the observed associations.

\section{Perspectives}

The perception of quality of life has been established as an efficient form of predicting cardiovascular events and survival rate in hypertensive patients. ${ }^{16}$ The results of the present study showed that some modifiable factors, such as muscle strength, body mass index, educational level and blood pressure influence the quality of life of these patients, and that has not been sufficiently investigated in the literature. Thus, in practical terms, interventions such as physical exercise and nutritional monitoring that promote previous control of these variables may positively affect the quality of life of hypertensive individuals. Additionally, it is suggested to carry out further studies to evaluate a broader sample of hypertensive patients, including individuals with other morbidities such as diabetes and dyslipidemia, and longitudinal studies evaluating quality of life, as well as its influence, for longer periods.

\section{Conclusion}

In conclusion, it was verified that hypertensive individuals with lower body mass index, higher educational level and muscle strength presented a better quality of life in the physical domain, while the social aspects have a positive relationship with educational level. Women report worse quality of life in the pain domain compared to men.

\section{Author contributions}

Conception and design of the research: Andrade-Lima A, Germano-Soares AH, Lima-Junior D, Rodrigues SLC,
Ritti-Dias RM, Farah BQ. Acquisition of data: Silva GO, Rodrigues SLC, Farah BQ. Analysis and interpretation of the data: Silva GO, Andrade-Lima A, GermanoSoares AH, Lima-Junior D, Rodrigues SLC, Ritti-Dias RM, Farah BQ. Statistical analysis: Silva GO, AndradeLima A, Germano-Soares AH, Ritti-Dias RM, Farah BQ. Obtaining financing: Rodrigues SLC, Ritti-Dias RM, Farah BQ. Writing of the manuscript: Silva GO, AndradeLima A, Germano-Soares AH, Lima-Junior D, Rodrigues SLC, Ritti-Dias RM, Farah BQ. Critical revision of the manuscript for intellectual content: Silva GO, AndradeLima A, Germano-Soares AH, Lima-Junior D, Rodrigues SLC, Ritti-Dias RM, Farah BQ.

\section{Potential Conflict of Interest}

No potential conflict of interest relevant to this article was reported.

\section{Sources of Funding}

This study was funded by Fundação de Amparo à Ciência e Tecnologia do Estado de Pernambuco (FACEPE APQ : 1177-4. 09/14)

\section{Study Association}

This study is not associated with any thesis or dissertation work.

\section{Ethics approval and consent to participate}

This study was approved by the Ethics Committee of the Universidade de Pernambuco (CEP-UPE) under the protocol number 30806014.0.0000.5207. All the procedures in this study were in accordance with the 1975 Helsinki Declaration, updated in 2013. Informed consent was obtained from all participants included in the study.

\section{References}

1. Gaui EN, Oliveira GMMd, Klein CH. Mortality by Heart Failure and Ischemic Heart Disease in Brazil from 1996 to 2011. Arq Bras Cardiol. 2014;102(6):557-65.

2. Mansur AP, Favarato D. Mortality due to cardiovascular diseases in Brazil and in the metropolitan region of Sao Paulo: a 2011 update. Arq Bras Cardiol. 2012;99(2):755-61.

3. Lewington S, Clarke R, Qizilbash N, Peto R, Collins R. Age-specific relevance of usual blood pressure to vascular mortality: a meta-analysis

of individual data for one million adults in 61 prospective studies. Lancet. 2002;360(9349):1903-13.

4. Picon RV, Fuchs FD, Moreira LB, Fuchs SC. Prevalence of hypertension among elderly persons in urban Brazil: a systematic review with metaanalysis. Am J Hypertens. 2013;26(4):541-8.

5. Ye R, Liu K, Zhang Z, Gong S, Chen X. Health-related quality of life of hypertension in China: a systematic review and meta-analysis. J Cardiovasc Med (Hagerstown). 2018;19(8):430-8. 
6. Kimmel PL. Just whose quality of life is it anyway? Controversies and consistencies in measurements of quality of life. Kidney International. 2000;57:113-20

7. Development of the World Health Organization WHOQOL-BREF quality of life assessment. The WHOQOL Group. Psychol Med. 1998;28(3):551-8.

8. Hays RD, Liu H, Spritzer K, Cella D. Item Response Theory Analyses of Physical Functioning Items in the Medical Outcomes Study. Med Care. 2007;45(5):S32-S8.

9. McHorney CA, Ware JE, Jr., Rogers W, Raczek AE, Lu JF. The validity and relative precision of MOS short- and long-form health status scales and Dartmouth COOP charts. Results from the Medical Outcomes Study. Med Care. 1992;30(5 Suppl):Ms253-65.

10. Stewart AL, Ware JE (editors). Measuring functioning and well-being: The medical outcomes study approach. London: Duke University Press: 1992.

11. Stewart AL, Hays RD, Ware JE Jr. The MOS short-form general health survey. Reliability and validity in a patient population. Med Care. 1988;26(7):724-35.

12. Veit CT, Ware JE Jr. The structure of psychological distress and well-being in general populations. J Consult Clin Psychol. 1983;51(5):730-42.

13. Croog SH, Levine S, Testa MA, Brown B, Bulpitt CJ, Jenkins CD, et al The effects of antihypertensive therapy on the quality of life. $N$ Engl J Med. 1986;314(26):1657-64.

14. Cote I, Grégoire J-P, Moisan J. Health-related quality-of-life measurement in hypertension. Pharmacoeconomics. 2000;18(5):435-50.

15. Ware J, Jr., Kosinski M, Keller SD. A 12-Item Short-Form Health Survey: construction of scales and preliminary tests of reliability and validity. Med Care. 1996;34(3):220-33.

16. Liang JW, Cheung YK, Willey JZ, Moon YP, Sacco RL, Elkind MSV, et al. Quality of life independently predicts long-term mortality but not vascular events: the Northern Manhattan Study. Qual Life Res. 2017;26(8):2219-28.

17. Nunes MI. The relationship between quality of life and adherence to treatment. Curr Hypertens Rep. 2001;3(6):462-5.

18. Souza ACCd, Borges JWP, Moreira TMM. Quality of life and treatment adherence in hypertensive patients: systematic review with metaanalysis. Rev Saúde Pública. 2016 Dec 22;50:71

19. Soutello ALS, Rodrigues RCM, Jannuzzi FF, São-João TM, Martinix GG, Nadruz Jr W, et al. Quality of life on arterial hypertension: Validity of Known Groups of MINICHAL. Arq Bras Cardiol. 2015;10(4):299-307.

20. Aydemir O, Ozdemir C, Koroglu E. The impact of co-morbid conditions on the SF-36: a primary-care-based study among hypertensives. Arch Med Res. 2005;36(2):136-41

21. Trevisol DJ, Moreira LB, Fuchs FD, Fuchs SC. Health-related quality of life is worse in individuals with hypertension under drug treatment: results of population-based study. J Hum Hypertens. 2012;26(6):374-80.

22. Mena-Martin FJ, Martin-Escudero JC, Simal-Blanco F, Carretero-Ares JL, Arzua-Mouronte D, Herreros-Fernandez V. Health-related quality of life of subjects with known and unknown hypertension: results from the population-based Hortega study. J Hypertens. 2003;21(7):1283-9.

23. Gopinath B, Kifley A, Liew G, Mitchell P. Handgrip strength and its association with functional independence, depressive symptoms and quality of life in older adults. Maturitas. 2017;106:92-4.

24. Assimakopoulos K, Karaivazoglou K, Tsermpini EE, Diamantopoulou G, Triantos C. Quality of life in patients with nonalcoholic fatty liver disease: A systematic review. J Psychosom Res. 2018 Sep;112:73-80.

25. Gobbens RJ, Luijkx KG, van Assen MA. Explaining quality of life of older people in the Netherlands using a multidimensional assessment of frailty. Qual Life Res. 2013;22(8):2051-61.

26. Farah BQ, Rodrigues SLC, Silva GO, Pedrosa RP, Correia MA, Barros MVG, et al. Supervised, but Not Home-Based, Isometric Training Improves Brachial and Central Blood Pressure in Medicated Hypertensive Patients: A Randomized Controlled Trial. Front Physiol. 2018 Jul 23;9: 961-70.
27. Ciconelli RM, Ferraz MB, Santos W, Meinão I, Quaresma MR. BrazilianPortuguese version of the SF-36. A reliable and valid quality of life outcome measure. Rev bras reumatol. 1999;39(3):143-50.

28. Lohman T, Roche A, Martorell R. Anthropometric standardization reference manual: Champaign: Human Kinetics Books; 1991.

29. Farah BQ, Correia MdA, Rodrigues SLC, Cavalcante BR, Ritti-Dias RM. Reliability of handgrip maximal voluntary contraction in hypertensive adults. Rev Bras Ativ Fís Saúde. 2014;19(5):590-6.

30. Malachias M, Souza W, Plavnik FL, Rodrigues C, Brandao AA, Neves M, et al. 7th Brazilian Guideline of Arterial Hypertension. Arq Bras Cardiol. 2016;107(3 Suppl 3):79-83.

31. Gerage AM, Benedetti TR, Farah BQ, Santana F da S, Ohara D, Andersen LB, et al. Sedentary behavior and light physical activity are associated with brachial and central blood pressure in Hypertensive patients. PLoS One. 2015;10(12):e0146078.

32. Wilson IB, Cleary PD. Linking clinical variables with health-related quality of life. A conceptual model of patient outcomes. JAMA 1995;273(1):59-65.

33. Stewart AL, Hays RD, Wells KB, Rogers WH, Spritzer KL, Greenfield S. Long-term functioning and well-being outcomes associated with physical activity and exercise in patients with chronic conditions in the Medical Outcomes Study. J Clin Epidemiol. 1994;47(7):719-30.

34. Xu X, Rao Y, Shi Z, Liu L, Chen C, Zhao Y. Hypertension Impact on Health-Related Quality of Life: A Cross-Sectional Survey among MiddleAged Adults in Chongqing, China. Int J Hypertens. 2016;2016:7404957.

35. Brennan SL, Turrell G. Neighborhood disadvantage, individual-leve socioeconomic position, and self-reported chronic arthritis: a crosssectional multilevel study. Arthritis Care Res (Hoboken). 2012;64(5):721-8.

36. Appel LJ, Champagne CM, Harsha DW, Cooper LS, Obarzanek E, Elmer PJ, et al. Effects of comprehensive lifestyle modification on blood pressure control: main results of the PREMIER clinical trial. JAMA. 2003;289(16):2083-93

37. Ho AK, Thorpe CT, Pandhi N, Palta M, Smith MA, Johnson HM Association of anxiety and depression with hypertension control: a US multidisciplinary group practice observational study. J Hypertens. 2015;33(11):2215-22.

38. Jasilionis D, Shkolnikov VM. Longevity and Education: A Demographic Perspective. Gerontology. 2016;62(3):253-62.

39. Bardage C, Isacson DG. Hypertension and health-related quality of life an epidemiological study in Sweden. J Clin Epidemiol. 2001;54(2):172-81.

40. Sayer AA, Syddall HE, Martin HJ, Dennison EM, Roberts HC, Cooper C Is grip strength associated with health-related quality of life? Findings from the Hertfordshire Cohort Study. Age Ageing. 2006;35(4):409-15.

41. Jakobsen LH, Rask IK, Kondrup J. Validation of handgrip strength and endurance as a measure of physical function and quality of life in healthy subjects and patients. Nutrition. 2010;26(5):542-50.

42. Trosclair D, Bellar D, Judge LW, Smith J, Mazerat N, Brignac A. HandGrip Strength as a Predictor of Muscular Strength and Endurance. The Journal of Strength \& Conditioning Research. 2011;25(Suppl 1):S99.

43. Garcia PA, Dias JMD, Dias RC, Santos P, Zampa CC. Estudo da relação entre função muscular, mobilidade funcional e nível de atividade física em idosos comunitários. Rev Bras Fisioter. 2011;15(1):15-22.

44. Awotidebe TO, Adeyeye VO, Ogunyemi SA, Bisiriyu LA, Adedoyin RA, Balogun $\mathrm{MO}$, et al. Joint predictability of physical activity and body weight status on health-related quality of life of patients with hypertension. J Exerc Rehabil. 2017;13(5):588-98.

45. Ogunlana MO, Adedokun B, Dairo MD, Odunaiya NA. Profile and predictor of health-related quality of life among hypertensive patients in south-western Nigeria. BMC Cardiovasc Disord. 2009 Jun 17;9:25.

46. Pan HJ, Cole BM, Geliebter A. The benefits of body weight loss on healthrelated quality of life. J Chin Med Assoc. 2011;74(4):169-75. 
47. Seidell JC. Obesity, insulin resistance and diabetes--a worldwide epidemic. Br J Nutr. 2000;83( Suppl 1):S5-S8.

48. Erickson SR, Williams BC, Gruppen LD. Perceived symptoms and healthrelated quality of life reported by uncomplicated hypertensive patients compared to normal controls. J Hum Hypertens. 2001;15(8):539-48

49. Erickson SR, Williams BC, Gruppen LD. Relationship between symptoms and health-related quality of life in patients treated forhypertension. Pharmacotherapy. 2004;24(3):344-50.

50. Erickson SR, Williams BC, Gruppen LD. Relationship between symptoms and health-related quality of life in patients treated for hypertension. Pharmacotherapy. 2004;24(3):344-50.

51. Dimenas ES, Wiklund IK, Dahlof CG, Lindvall KG, Olofsson BK, De Faire UH. Differences in the subjective well-being and symptoms of normotensives, borderline hypertensives and hypertensives. J Hypertens. 1989;7(11):885-90.

52. Cuffee Y, Ogedegbe C, Williams NJ, Ogedegbe G, Schoenthaler A. Psychosocial risk factors for hypertension: an update of the literature. Curr Hypertens Rep. 2014;16(10):483.
53. Malachias M, Póvoa R, Nogueira A, Souza D, Costa L, Magalhães M. 7th Brazilian Guideline of Arterial Hypertension: Chapter 3 - Clinical and Complementary Assessment. Arq Bras Cardiol. 2016;107(3 Suppl 3):14-7.

54. Tsai JC, Yang HY, Wang WH, Hsieh MH, Chen PT, Kao CC, et al. The beneficial effect of regular endurance exercise training on blood pressure and quality of life in patients with hypertension. Clin Exp Hypertens. 2004;26(3):255-65

55. Cornelissen VA, Smart NA. Exercise training for blood pressure: a systematic review and meta-analysis. J Am Heart Assoc. 2013;2(1):e004473.

56. Bingefors K, Isacson D. Epidemiology, co-morbidity, and impact on health-related quality of life of self-reported headache and musculoskeletal pain--a gender perspective. Eur J Pain. 2004;8(5):435-50.

57. Palmeira CCdA, Ashmawi HA, Posso IdP. Sexo e percepção da dor e analgesia. Rev Bras Anestesiol. 2011;61(6):820-8 